\title{
First phylogenetic analysis of the tribe Oligaphorurini (Collembola: Onychiuridae) inferred from morphological data, with implications for generic classification
}

\author{
Grzegorz Paśnik $^{1}$ • Wanda M. Weiner ${ }^{1}$
}

Received: 28 August 2016 / Accepted: 24 May 2017 /Published online: 13 June 2017

(C) The Author(s) 2017. This article is an open access publication

\begin{abstract}
Oligaphorurini represent tribe of the subfamily Onychiurinae, which currently comprises 5 genera and 53 species. The present study evaluated the monophyly of Oligaphorurini genera. We investigated phylogenetic relationships among 39 species, representing all extant genera of Oligaphorurini. Both equal- and implied-weighting parsimony analyses were used in phylogenetic reconstruction. The cladistic analyses were based on comprehensive survey of adults' morphological characters because specimens suitable for molecular studies were not available for the majority taxa. The phylogenetic analysis resulted in the recognition of a monophyletic Chribellphorura, and strongly supported nonmonophyly of the previously recognized genera Archaphorura, Dimorphaphorura, Micraphorura, and Oligaphorura. The following new synonymy is recognized: Oligaphorura = Dimorphaphorura syn. nov., = Micraphorura syn. nov., = Archaphorura syn. nov. The general classification of Oligaphorurini is followed by the diagnoses of genera and key to the all known species.
\end{abstract}

Keywords Phylogeny · Implied weighting • Taxonomy • Classification $\cdot$ Identification key

Electronic supplementary material The online version of this article (doi:10.1007/s13127-017-0332-8) contains supplementary material, which is available to authorized users.

Grzegorz Paśnik

pasnik@isez.pan.krakow.pl

1 Institute of Systematics and Evolution of Animals, Polish Academy of Sciences, Sławkowska 17, 31-016 Kraków, Poland

\section{Introduction}

The Oligaphorurini comprises 53 species restricted in occurrence to Holarctic Region (Bellinger et al. 2016). The tribe was established by Bagnall (1949) as a subfamily and characterized by a small postantennal organ with a 3-5 lobed vesicle, the specific structure of the antennal organ, the presence and arrangement of pseudocelli on the head, and the presence/ absence of anal spines. Bagnall divided the tribe into four genera (Archaphorura, Dimorphaphorura, Micraphorura, and Oligaphorura) and presented diagnosis, which did not allow for clear differentiation of genera. Most of twentiethcentury authors have, however, considered all created genera as junior synonyms of Onychiurus Gervais, 1841.

In 1996, four original genera described by Bagnall were recovered by Weiner whereas Pomorski recovered three genera (he has not included Dimorphaphorura into his classification). Both authors, using different approaches (Pomorski studied the first instar juveniles, while Weiner used adults), base their diagnosis on the organization of furcal remnant located in mid-section of fourth abdominal segment. According to these authors, Archaphorura was defined by the absence of anal spines, Dimorphaphorura by furcal remnant in a form of finely granulated area with four dental setae in one row, Micraphorura by furcal remnant in a form of cuticular furrow and two dental setae (= setulae sensu Pomorski) and Oligaphorura by furcal remnant in a form of cuticular fold and four dental setae.

Weiner, in the same work, also established the genus Chribellphorura based on two unique characters: antennal segment IV with apical vesicle and tibiotarsi with clavate setae in distal whorl.

In recent years, it has been described a few new species that have morphological features previously considered to be characteristic of other genera. Shvejonkova and Potapov (2011) 
and Babenko and Fjellberg (2015) described in the genera Micraphorura and Oligaphorura five new species which possess features characteristic for Archaphorura (absence of anal spines) and Dimorphaphorura (furcal rudiment in the form of a finely granulated area).

In this way, all genera lost their diagnostic features. Moreover, none of the authors did not establish the synonyms and did not proposed new generic diagnosis or proposed overlapping diagnosis (Shvejonkova and Potapov 2011). In this situation, all genera are very poorly or not at all defined and species belonging to the genera is determined subjectively.

Difficulties in the generic classification of the Oligaphorurini are partly a result of the diversity and morphological complexity of the group. The systematic position of Oligaphorurini genera is still in state of flux, and the relatively frequent changes in position of many taxa reflect their unstable classification.

Until now, no comprehensive attempt has been made to resolve the generic concept within Oligaphorurini. Relationships among the genera are largely unknown. Taxonomically, the tribe has changed almost exclusively through the addition of newly described taxa that resulted in various classifications based on dubious assemblages using relatively few characters. The taxonomic characters used in classifications of Oligaphorurini genera are now known to be shared among members of the tribe and may have produced a classification having little phylogenetic basis.

The current study aims to evaluate the validity of Oligaphorurini genera because most of them are vaguely defined and not always based on the presence of derived character states. The analyses were carried out using cladistic methods, with morphology of adult stages as the data source, because specimens suitable for molecular studies were not available for the majority taxa.

\section{Material and methods}

\section{Taxon sampling}

Thirty-nine species representing all currently recognized genera of the tribe Oligaphorurini were included in this study: two species of Archaphorura (two of three known species), the only known species of Chribellphorura, 17 species of Dimorphaphorura (17 of 20 known species), five species of Micraphorura (five of eight) and 14 species of Oligaphorura (14 of 21). As far as possible, we have examined type specimens in order to ensure the accuracy of names applied to terminal taxa. Sampled species were chosen as to reflect the maximum of morphological diversity within genera and its geographical distribution.

The outgroup consisted of three taxa representing three tribes in the Onychiurinae: Onychiuroides granulosus (Stach
1930), Thalassaphorura encarpata (Denis 1931), and Protaphorura eichhorni (Gisin 1954). The tree was rooted on $O$. granulosus.

\section{Morphological data}

A total of 63 characters were scored for the study taxa, including 36 binary characters and 27 multistate characters (Appendix 1). Autapomorphies were retained in the data matrix (Yeates 1992), as they might probably become synapomorphies when new taxa are described and taxon sampling improves, but were deactivated for the calculation of ensemble value of consistency index (CI) as proposed by Bryant (1995). Missing data were coded as "?" in the matrix (Appendix 2). All characters were treated as unordered (Fitch 1971) and equally weighted (Wilkinson 1992).

Characters states were evaluated directly on specimens of majority species, with the exception of species that are either rare in collections or at least unavailable to the authors (Appendix 2). For these species, information was gathered from published descriptions and illustrations.

Specimens were examined and illustrated using a Leica DMLB compound microscope with a drawing tube. Digital microscope images were recorded using a Leica DFC420 digital camera attached to the microscope. Morphological terminology is largely based on Fjellberg (1999) (labial papillae types), Pomorski (1998), and Weiner (1996) (furcal area).

The character matrix was compiled and characters mapped with WinClada ver. 1.00.08 (Nixon 2002) to observe character state transformation on a given tree.

\section{Phylogenetic analysis}

The parsimony analyses were conducted in TNT ver. 1.4 (Goloboff et al. 2008) using both equal weighting and implied weighting. Trees were searched using a heuristic strategy ("traditional search") comprising 1000 replicates of a stepwise addition procedure with random sequence, followed by treebisection-reconnection (TBR) branch swapping of a maximum of 10 trees. The maximum number of trees held was set to 10,000 .

The stability of the result in equally weighted maximum parsimony analysis was assessed by performing analyses under implied weighting (Goloboff 1993; Giribet 2003). Implied weighting in TNT weights the characters according to a concave function of homoplasy (Goloboff 1993). We used four different concavity factor values $(k=3,6,9,12)$ to explore the sensitivity of topology under varying weighting conditions. The implied weight searches used the same parsimony options.

Clade supports were assessed based on Bremer support (Bremer 1994) and symmetric resampling (Goloboff et al. 2003). The Bremer support value was calculated by searching 
suboptimal trees up to 10 steps longer than the shortest one using TBR swapping on the shortest trees. Up to 10,000 suboptimal trees were retained during each turn.

The Symmetric Resampling support calculated the differences in the frequencies of a given group and its most frequent contradictory group (GC). The analyses were run in TNT with the traditional search, using 10,000 replications, change probability of 0.33 , two initial Wagner trees, and holding three trees per replicate.

The support methods were employed in both the equal weighting and the implied weighting searches. The synapomorphies were mapped in WinClada onto the most parsimonious tree using an option showing unambiguous changes only.

\section{Results}

Maximum parsimony analysis of the morphological dataset under equal weights resulted in two most parsimonious trees with a length of 302 steps $(\mathrm{CI}=0.31 ; \mathrm{RI}=0.61)$, and the strict consensus and branch support values are shown in Fig. 1. The strict consensus tree is used as the working hypothesis for oligaphorurines. Autapomorphic or unambiguous synapomorphic morphological changes are presented in Fig. 2.

Heuristic searches in TNT under implied weighting using the above search parameters found twelve trees for $k=3$ and one tree for each remaining $k$ values studied $(6,9$, and 12$)$. The consensus tree obtained from the analyses with $k=3$ differs considerably from these under equal weights. The impliedweighting cladograms with values of $k=6,9$, and 12 produced similar topologies (Fig. 3), with a total number of 302 steps, a consistency index of 0.302 , and a retention index of 0.60 . Although the general topology was consistent among all of the resulting trees, the cladistic relationships varied within the species groups.

According to the results of the phylogenetic analysis, the genus Chribellphorura was confirmed as a monophyletic group although only with moderate support (Figs. 1 and 2). In the equal- and implied-weighting parsimony analyses, the genus was supported by the following character states: antennal segment IV with apical vesicle (character 9; unambiguous), antennal organ III with four papillae (character 15; ambiguous), antennal organ III with four guard setae (character 16; unambiguous), thoracic tergite II with two pseudocelli (character 22; ambiguous), thoracic tergite III with two pseudocelli (character 23; ambiguous), abdominal tergite I with two pseudocelli (character 29; ambiguous), tibiotarsi with clavate setae in distal whorl (character 57; unambiguous).

In the analysis, the remaining Oligaphorurini genera (Archaphorura, Dimorphaphorura, Micraphorura, and Oligaphorura) appeared as non-monophyletic.
Chribellphorura appeared in a basal position within the tribe, with the rest of the genera then arranged in a three clades.

Clade A consists of six species from the genera Oligaphorura, Archaphorura, and Dimorphaphorura (Fig. 1). This clade was supported by five character states, but only one of which represent unambiguous character change: subcoxa of II and III legs with two to three pseudocelli (character 59) (Fig. 2).

Clade B comprises all of the Micraphorura species, majority of Oligaphorura and one species of Archaphorura (Fig. 1). The group was supported by the presence of furcal remnant in a form of cuticular fold or furrow (character 49; ambiguous) (Fig. 2).

Clade C is composed of 16 species from the genus Dimorphaphorura (all species except one which falls into clade A) + Oligaphorura groenlandica (Fig. 1). This clade was supported by the following character states: clubs of sense organ of the third antennal segment differentiated, one granulated and one ribbed (character 12; ambiguous), tibiotarsi with nine setae in distal whorl (character 61, ambiguous) (Fig. 2).

\section{Discussion}

In this study, the strict consensus tree obtained by the equalweighting analysis was used to infer the phylogenetic relationships among the genera of Oligaphorurini as the topology of the consensus tree did not differ significantly from the implied-weighting trees. Because the main goal was to clarify the monophyly of the currently recognized genera, slight variations in tree topology were not considered important.

\section{Monophyly of Chribellphorura}

The Chribellphorura is the only genus recovered in the analysis as monophyletic. This monotypic genus is distinguished by two autapomorphies: antennal segment IV with apical vesicle, antennal organ III with four guard setae and tibiotarsi with clavate setae in distal whorl. However, it did not share with the rest members of Oligaphorurini (except $O$. ambigua) enlarged antennal segments III and IV which form distinct club (Pomorski 1998).

\section{Monophyly of Archaphorura}

The monophyly of Archaphorura was not recovered in our study. The genus is composed of three species, two of which were included in the analysis. Archaphorura serratotuberculata, the type species of the genus, is nested within the species of Oligaphorura in the clade B (Fig. 1). This species is characterized by three unique autapomorphies: antennal segments III and IV accreted ventrally (character 10), sense organ of the third antennal segment in subapical position

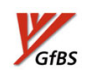




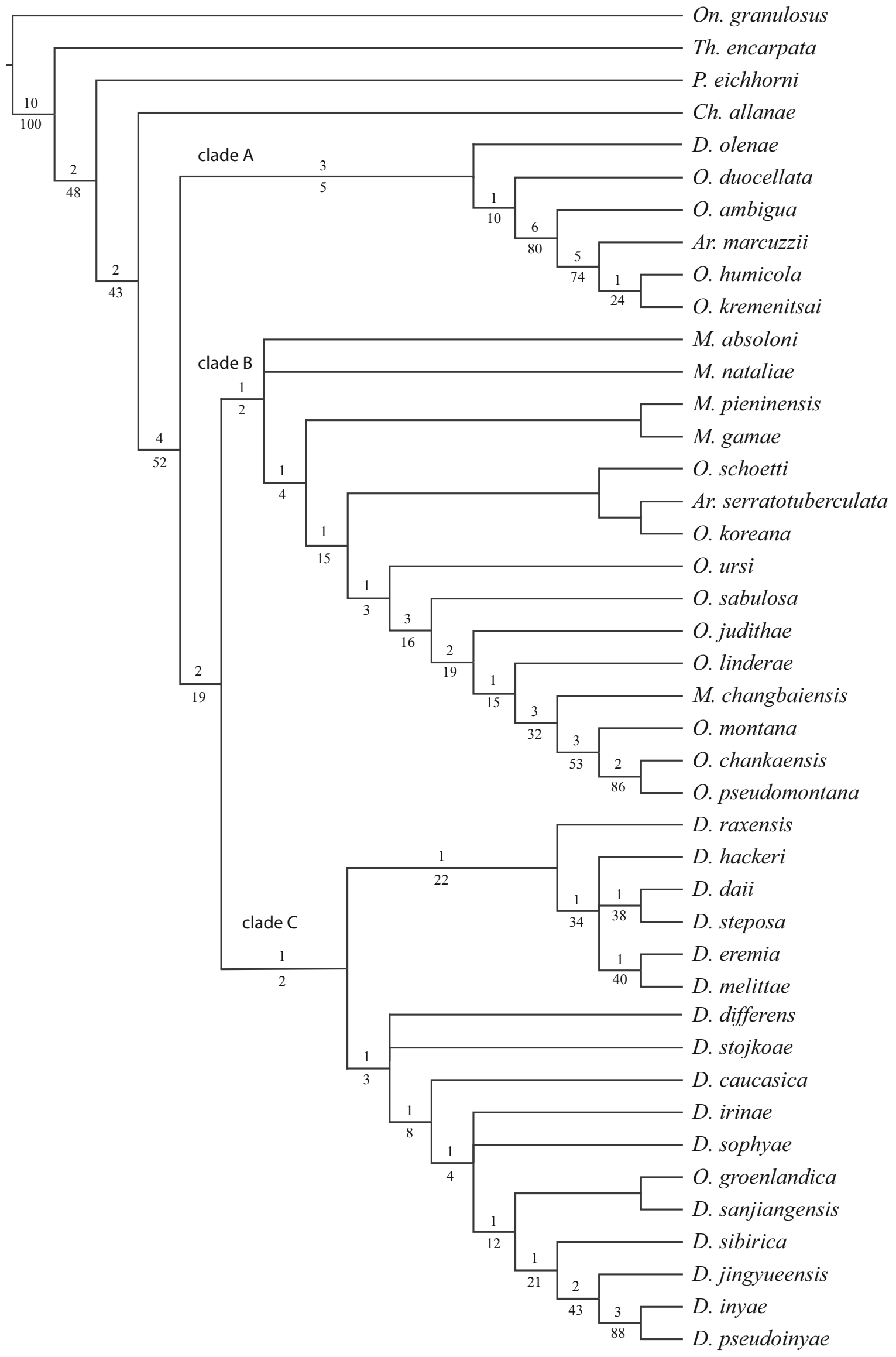


4 Fig. 1 Strict consensus of two most parsimonious trees resulting from the analysis of the morphological dataset under equal weight $(L=302$; $\mathrm{CI}=0.31 ; \mathrm{RI}=0.61)$. Numbers above each node indicate Bremer support (BS); numbers below each node indicate symmetric resampling

(character 11), abdominal tergites V and VI fused dorsally (character 37) (Fig. 2). The second studied species, Archaphorura marcuzzii, did not share these autapomorphies and was placed in clade A (Fig. 1).

Besides a unique character combination of type species, Archaphorura was also characterized by the absence of anal spines (in contrast to all remaining genera). However, recently described species without anal spines were placed in the genera Oligaphorura and Micraphorura (Shvejonkova and Potapov 2011; Babenko and Fjellberg 2015) thereby depriving genus its main diagnostic feature. In all other respects, especially in the form of furca remnant, it is congruent with the species of Oligaphorura.

\section{Monophyly of Micraphorura and Oligaphorura}

The monophyly of these two genera is not supported by the present work. All species of Micraphorura and majority species of Oligaphorura are clustered together within clade B (Fig. 1). The remaining species of Oligaphorura are placed in clade A and $O$. groenlandica, the type species of the genus, is placed in clade $\mathrm{C}$ (Fig. 1).

Traditionally, both genera were recognized almost exclusively on the basis of the build of furcal remnant. Oligaphorura was characterized by the presence of cuticular fold and four so-called dental setae arranged in two rows as $2+2$ (Fig. 4a, b), whereas Micraphorura has cuticular furrow and two "dental" setae in one row (Fig. 4c).

The term "dental setae" was introduced (Weiner 1996) to describe the setae located on dental area (= cuticular fold) or just behind in first row of manubrial setae (row "ma") and differing in the size and/or the size of its socket (= setulae according to Pomorski 1996, 1998). The character was recently debated by Babenko and Fjellberg (2015), who stated that this feature is subjective and so-called dental setae differ from other sternal setae on abdominal segment 4 only occasionally. Our studies confirm that these setae show intra- and interspecific variability.

The further complications bring recently described species of Oligaphorura and Micraphorura (Shvejonkova and Potapov 2011; Babenko and Fjellberg 2015) which do not have furca reduced to cuticular fold or furrow but small area of fine granulation, feature which is characteristic for Dimorphaphorura. Thus, several different patterns of furcal rudiment can be found among species of these two genera.

Moreover, O. groenlandica, the type species of the Oligaphorura, falls outside of the other sampled species of the genus and is placed together with the members of
Dimorphaphorura into clade C (Fig. 1). Previously, there were some misunderstandings regarding the diagnosis of Oligaphorura presented by Pomorski (1996, 1998), Fjellberg (1998), and Weiner (1996). This species has furcal area without cuticular fold or deep pocket considered as a characteristic of the genus but an area with fine granulation in anterior third of the abdominal sternum IV (typical for the species of Dimorphaphorura). In the material recently collected on Spitzbergen, we found the specimens with a fine granulated area which the posterior edge seems to be folded with coarser granulation.

\section{Monophyly of Dimorphaphorura}

The genus Dimorphaphorura was recovered as nonmonophyletic in both the equal- and implied-weighting parsimony analyses. Although all but one species of Dimorphaphorura are clustered together in clade $\mathrm{C}$, the support for this resolution is low (Figs. 1 and 2).

The genus was recovered by Weiner (1996) and recently revised by Weiner and Kaprus' (2014) who provided diagnostic characteristics of the genus. The authors defined it on the base of organization of the furcal area: furcal remnant in a form of finely granulated area with three rows of setae behind and lack of dental setae. The generic status of Dimorphaphorura was recently questioned by Shvejonkova and Potapov (2011). As mentioned above, all characters used to define genus are variable and scattered in different combination across genera.

\section{Monophyly of Oligaphorurini}

As the main objective of this study was to investigate the relationships of Oligaphorurini genera, the taxon sampling of the remaining Onychiurinae tribes is sparse. Nevertheless, the results of our studies allow for some conclusions to be drawn regarding the status of the tribe.

In the equal- and implied-weighting parsimony analyses, the Oligaphorurini was recovered as monophyletic although only with moderate support (Figs. 1 and 2). The tribe was supported by two unambiguous character changes: postantennal organ composed of one vesicle (character 3 ) and postantennal organ vesicle divided into three to five lobes (character 4).

Traditionally, Oligaphorurini (as all other tribes of Onychiurinae) have previously been defined by character combination, which mainly include: the shape of postantennal organ, build of sense organ of the third antennal segment, presence/absence of pseudocelli and anal spines, the reduction of furca, chaetotaxy of tibiotarsi, and distribution of sensory setae on the body.

A growing number of the described species with intermediate combinations of features compared to previously known ones makes tribes also becoming less characterized. Most of the morphological characters are variable and segregated 

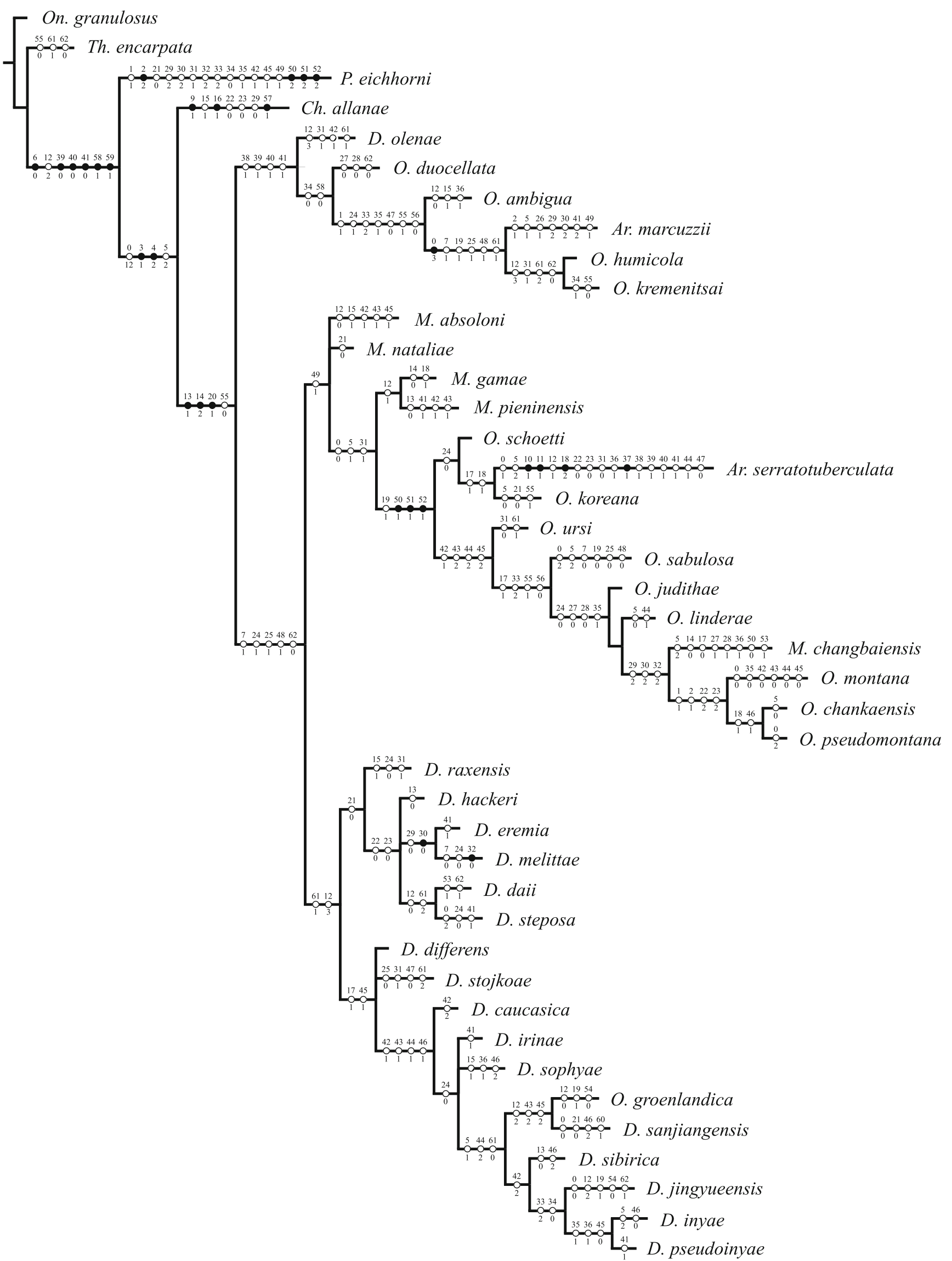
Fig. 2 Unambiguous morphological character optimization onto the strict consensus tree. Numbers above and below circles on the branches indicate character numbers and states, respectively. White and black circles represent homoplasious and nonhomoplasious states, respectively

across genera. Some of this features so far considered useful is not working any more. The validity of currently recognized tribes also required detailed studies.

Cladistic analysis of the tribe Oligaphorurini presents some serious problems regarding character discovery and coding. This is compounded by Onychiurinae systematics being generally difficult due to close morphological similarity of species and a paucity of informative characters at this level of classification. The preferred phylogeny is preliminary but can serve as a working hypothesis of the evolutionary relationships within the study groups. Future studies on the phylogeny of Oligaphorurini (and Onychiurinae) should focus on molecular systematics with comprehensive sampling.

\section{Furcal remnant}

The reduction of the furca and organization of its elements was considered as one of the most important characters to discriminate between genera of Oligaphorurini. The character was introduced by Weiner (1996) and Pomorski (1996) in their works on systematics of Onychiurinae. According to these authors, the genera maybe recognized as follows: Archaphorura and Oligaphorura possess cuticular fold and four dental setae arranged in two rows as $2+2$ (Fig. 4a, b), Micraphorura has cuticular furrow and two dental setae in one row (Fig. 4c), whereas Dimorphaphorura has furcal remnant as a finely granulated area and is devoid of dental setae (Fig. 4e). For years, this scheme was widely used in the systematics of Oligaphorurini.

Recently published papers (Shvejonkova and Potapov 2011; Babenko and Fjellberg 2015), presenting descriptions of new species with furcal features arranged in a different way, caused the collapse of the entire system (see above). Additionally, the latter authors criticize the use of reductional stages of the furca as an almost exclusive diagnostic feature, arguing that similarity in reductional stage may represent a convergence and many collembolan genera cover species with a wide range of furcal reduction.

The results of our study confirm that the furcal remnant seems to have smaller generic value than have been assumed so far. Nevertheless, the construction of furcal area provides
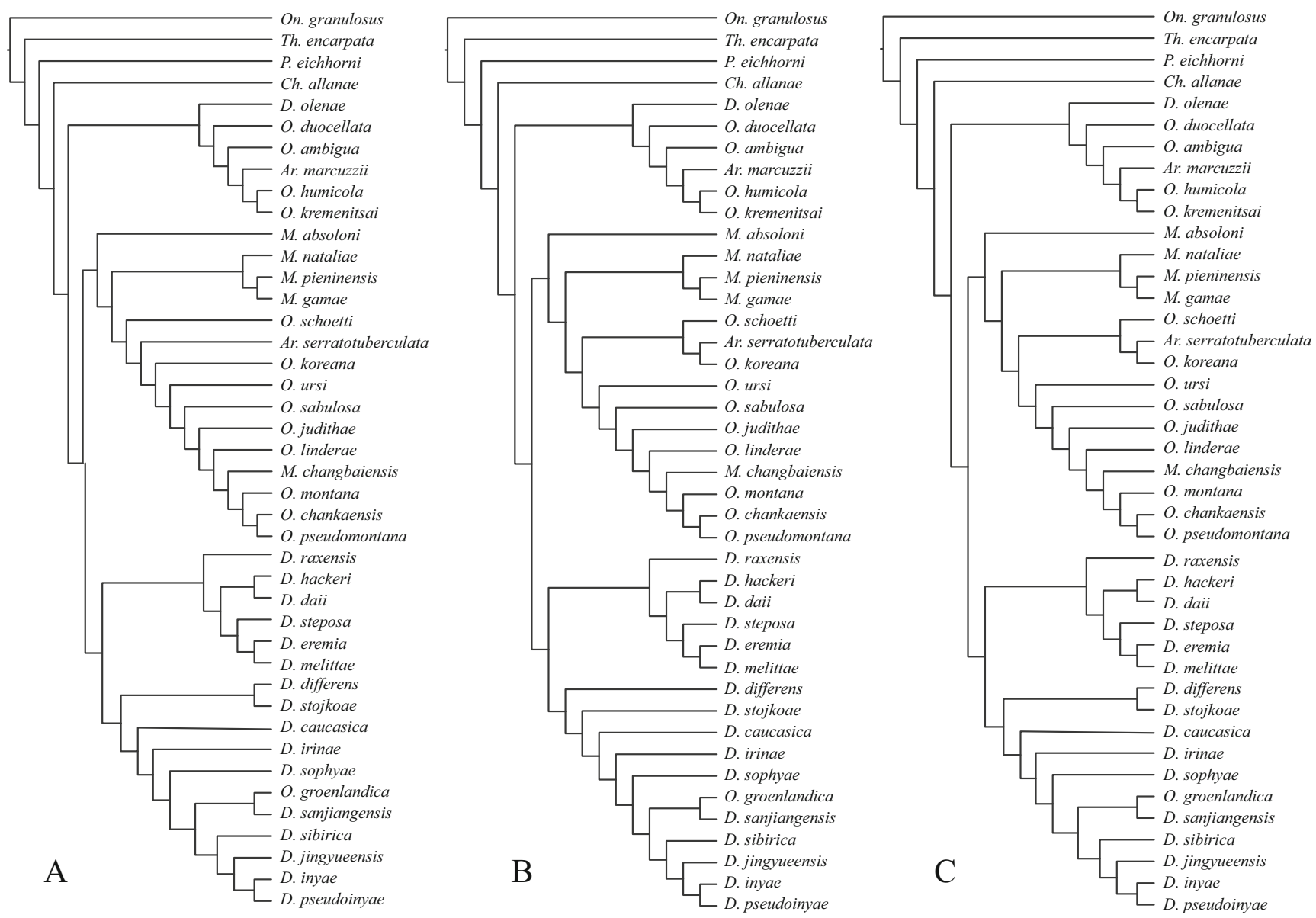

Fig. 3 Trees obtained under the implied weighting using three concavity values $k=6$ (a), 9 (b), and 12 (c) 
Fig. 4 Abdominal sternite IV showing organization of furcal remnant. a, b Oligaphorura ursi Fjellberg, 1984; c Micraphorura gamae Bușmachiu and Weiner, 2013; d Oligaphorura groenlandica (Tullberg, 1876); e Dimorphaphorura inya Weiner and Kaprus, 2014; f Protaphorura eichhorni (Gisin, 1954)
A

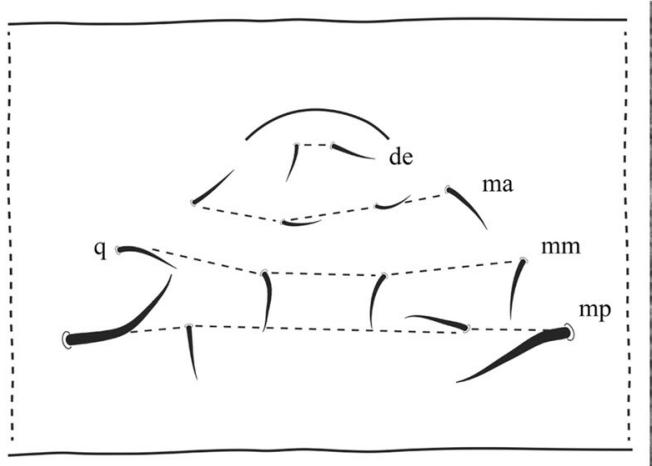

C

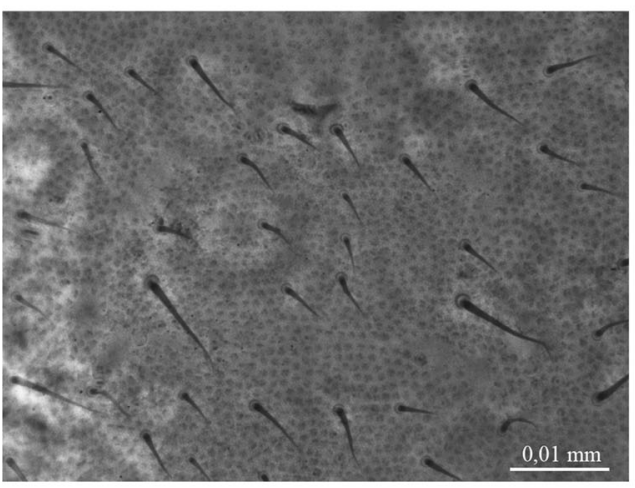

$\mathrm{E}$

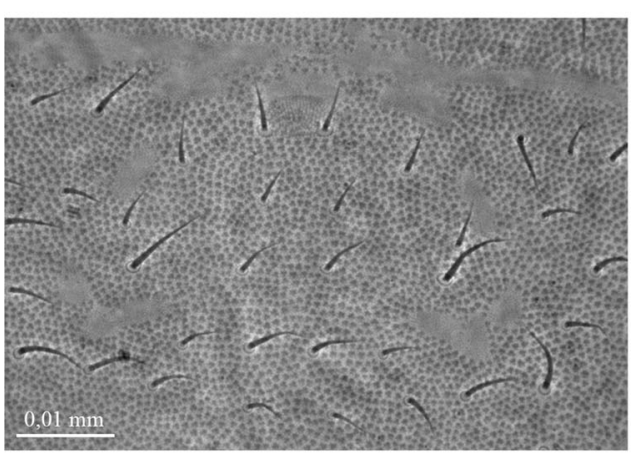

B

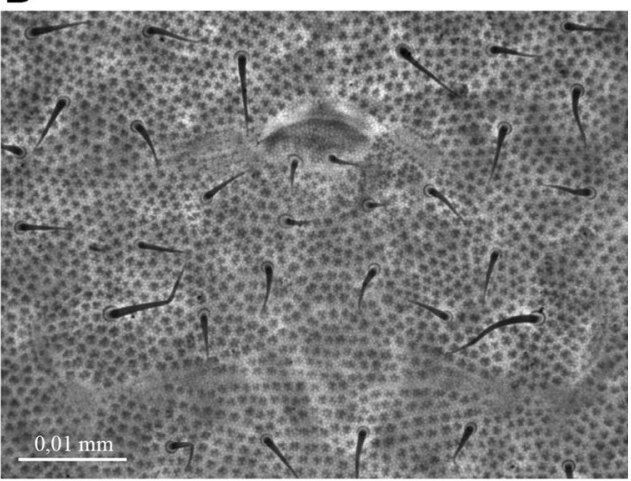

D

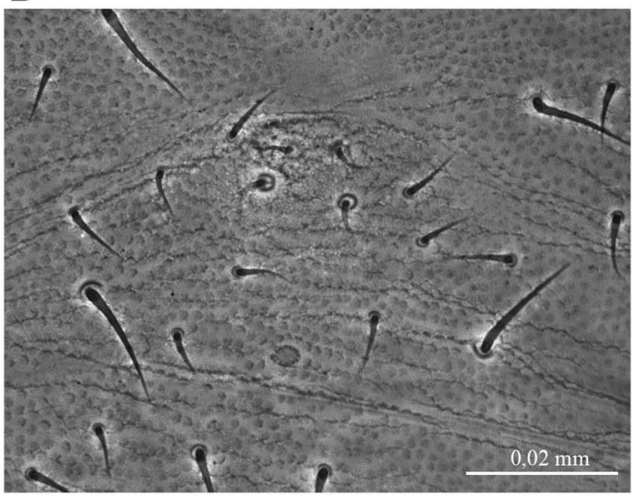

$\mathrm{F}$

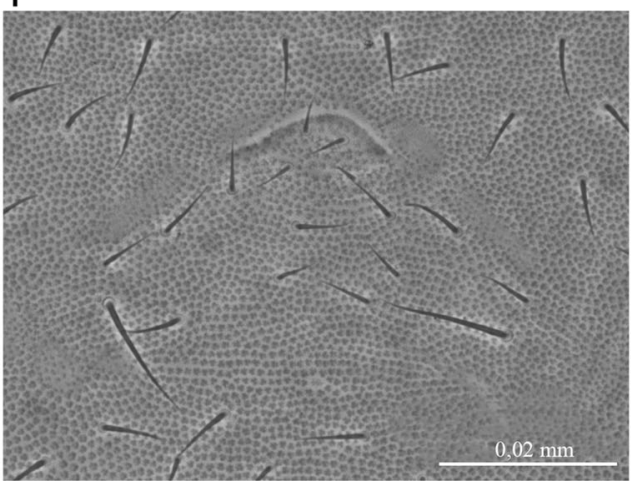

many useful features that can be used successfully at the level of species or groups of species.

Although this feature has been used for years in the systematics of Oligaphorurini, there is no uniform pattern of description of this structure. This is particularly evident in recent years when the system was clarified. Different authors use different terminology and classify the individual manubrial setae to different rows. This ensures that the system is less and less comparable.

In this work, we have tried to organize the system, taking into account the recent criticism. The furcal remnant can be divided into dental vestige and manubrial area (Fig. 4a). The first one is typically located in mid-section of abdominal segment 4 and can be developed as a cuticular fold (Fig. 4a, b, f), cuticular furrow (Fig. 4c), or a finely granulated area (Fig. 4d, e).
The manubrial area is comprised of setae typically arranged in three rows (Fig. 4a). The $m p$-row is located just above pseudopore and is defined by the two outer macrosetae. Above it is the $m m$-row of setae which is defined by two outer " $q$ " setae (sensu Pomorski 1996). These two rows may count from four to five (most common) to seven setae (rarely). At the top is a ma-row which can count from two to four setae. The so-called dental setae, because of their variability, are no longer recognized by their size or size of their socket. We decided that the dental setae are only these that are located on the cuticular fold (Fig. 4a). The dental setae of the second row (regardless of the size), which are typically placed on manubrial area, are here included in the $m a$-row without naming them as "dental." This is a typical arrangement, easily recognizable, and occurs in most species. In some cases, there 
are additional rows of setae between $m a$ - and $m m$-rows, which are then referred to as $m m^{\prime}$-row(s) (Fig. 4f). Because these additional rows are often not arranged regularly and often have chaotically multiplied setae, we decided not to assign them to individual rows ( $m a^{\prime}, \mathrm{mm}^{\prime}, \mathrm{mm}^{\prime}$ ", etc.) but treat them all as $m m^{\prime}$-row(s).

\section{Taxonomic implications}

Based on the present analysis, there are two ways to remedy the classification. One is to simply leave the current fivegenera system, redefine recognized genera, and transfer species to such characterized groups. Unfortunately, such a solution is incompatible with the results obtained by us and contrary to the principle according to which only monophyletic taxa are valid. Furthermore, without the explicit and clear definition of the genera and because of the different views on generic membership of each species, there is a risk that the species will be classified to the different genera subjectively, depending on the point of view of the author. Even now, there are clear differences in views on the classification of species which leads to constant changes in the systematics of Oligaphorurini. In our opinion, the maintenance of the current system will lead to increasing mess in the taxonomy of this group.

It seems to be reasonable to make changes in the systematics of Oligaphorurini and synonymize genera according to the obtained results. Babenko and Fjellberg (2015) stated that pooling of all species of the tribe within a single unit obviously contradicts recent taxonomic traditions. We do not share this opinion. Synonimization may not be the perfect solution but given the current state of our knowledge and the available information, it is a system that will serve best.

The general classification given below includes the oligaphorurines' relationships that result from the analyses discussed above and is followed by the diagnoses of genera and key to the all known species.

Tribe Oligaphorurini Bagnall, 1949

Oligaphorurinae Bagnall, 1949: 507

Type genus: Oligaphorura Bagnall, 1949: 510

Diagnosis. Postantennal organ with one vesicle divided into three to five (six) lobes. Species of minute to moderate size $(0.4-1.7 \mathrm{~mm})$

Taxonomic notes. When establishing the Oligaphorurinae (= Oligaphorurini), Bagnall (1949) did not specify the type genus. According to the ICZN (Art. 11.7 and 29), the name should be formed from the stem of an available generic name and the proper suffix. Additionally, the type genus should be both well known and representative of the family-group taxon, not necessarily that having the oldest name (Art. 64). Therefore, in the interest of stability of nomenclature and according to ICZN, the genus Oligaphorura was chosen as type genus for Oligaphorurini.
Genus Chribellphorura Weiner, 1996

Chribellphorura Weiner, 1996: 174

Type species: Onychiurus (Archaphorura) allanae Christiansen and Bellinger, 1980: 405

Diagnosis. Postantennal organ with one vesicle divided into five lobes. Antennal segment IV with apical vesicle, sense organ of the third antennal segment with four papilla and four guard setae. Posterior pseudocelli on the head present. Labial palp of 0-type. Thoracic tergite I with one pseudocellus, tergites II and III with two pseudocelli. Abdominal tergite I with two pseudocelli, furcal remnant as a finely granulated area with three rows of setae posteriorly. Tibiotarsi with clavate setae in distal whorl. Anal spines present.

Genus Oligaphorura Bagnall, 1949

Oligaphorura Bagnall, 1949: 510

Type species: Lipura groenlandica Tullberg, 1876: 41

Archaphorura Bagnall, 1949: 508 syn. nov.

Type species: Onychiurus serratotuberculatus Stach, 1933: 238

Dimorphaphorura Bagnall, 1949: 510 syn. nov.

Type species: Dimorphaphorura differens Bagnall, 1949: 510

Micraphorura Bagnall, 1949: 509 syn. nov.

Type species: Aphorura absoloni Börner, 1901b: 422

Diagnosis. Species of minute or moderate size, with small postantennal organ (one vesicle with three to five lobes). Antennal apical vesicle absent. Sense organ of the third antennal segment usually with sensory clubs of different size. Tibiotarsal distal whorl with 11 or fewer (9-5) acuminate setae. Labial palp of different types (ABC, AC, A, ABD). Head with posterior pseudocelli present, thoracic tergum I with (one, rarely more) or without pseudocelli. Furcal remnant as a cuticular fold, cuticular furrow or finely granulated area with three to four manubrial rows of setae, dental setae present (two setae) or absent. Anal spines present or absent.

\section{Key to the species of the tribe Oligaphorurini}

Abbreviations used in the key: AIIIO, sense organ of the third antennal segment; Ant, antennal segment; PAO, postantennal organ; Th, thoracic segment; Abd, abdominal segment; pso, pseudocellus/pseudocelli; psx, parapseudocellus/parapseudocelli.

1. Tibiotarsi with acuminate setae............2 (Oligaphorura Bagnall, 1949)

-Tibiotarsi with clavate setae... Chribellphorura allanae (Christiansen and Bellinger, 1980)

2. Anal spines absent ...................................................... 3

-Anal spines present ....................................................... 9

3. Th. terga I-III with 133 pso ......................................... 4

-Th. terga I-III with 144 pso ............................................. 8

4. Head dorsally with 32 pso ....................................... 5 
-Head dorsally with 42 pso 7 5. Abd. terga I-V with 44463 pso ..alavensis (Simón, 1994) comb. nov.

-Abd. terga I-V with 33343 pso 6

6. Tibiotarsal distal whorl with seven setae, furcal remnant without cuticular furrow. stojkoae

(Shvejonkova and Potapov, 2011) comb. nov.

-Tibiotarsal distal whorl with 11 setae, furcal remnant with cuticular furrow. serratotuberculata (Stach, 1933)

7. AIIIO with 5 papillae humicola Shvejonkova and Potapov, 2011

-AIIIO with 4 papillae ambigua Babenko and Fjellberg, 2015

8. Abd. terga I-V with 33354 pso, subcoxae 1 of legs I-III with 222 pso.. kremenitsai

Shvejonkova and Potapov, 2011

-Abd. terga I-V with 44454 pso, subcoxae 1 of legs I-III with 111 pso marcuzzii

(Cassagnau, 1968)

9. Head with 32(1) pso 10

-Head with more pso 52

10. Head posteriorly with $2+2$ pso 11

-Head posteriorly with $1+1$ pso, body with $133 / 44444$ pso, subcoxae 1 with 111 pso... gela

(Christiansen and Bellinger, 1980)

11. Th. tergum I without pso ...................................... 12

-Th. tergum I with pso ............................................. 26

12. Th. terga II and III with 22 pso ............................. 13

-Th. terga II and III with more pso .............................. 17

13. Abd. I-V with 33343 pso .................................... 14

- Abd. I-V with 22243 or 22343 pso ........................... 16

14. Th. tergum II with s-microsetae (ms), Th. tergum III without s-microsetae (ms), Abd. sternum IV without pso ..... 15

-Th. terga II and III with s-microsetae (ms), Abd. sternum IV with $1+1$ pso, tibiotarsal distal whorl with five setae.....steposa (Kaprus' et al., 2002) comb. nov.

15. Tibiotarsal distal whorl with nine setae......hackeri Christian, 1986

- Tibiotarsal distal whorl with six setae........daii (Pomorski et al., 1998) comb. nov.

16. Abd. terga I-V with 22243 pso, Abd. sternum IV without pso, Th. tergum III with or without s-microsetae (ms) ..................... melittae Christian, 1993 -Abd. terga I-V with 22343 pso, Abd. sternum IV with $1+1$ pso, Th. tergum III without s-microsetae (ms)......eremia (Kaprus' et al., 2002) comb. nov.

17. Abd. terga I-V with 44454 pso ............................. 18 -Abd. terga I-V with 33333,33343 or 33353 pso ........ 19 18. Abd. terga I-III with unusual arrangement of pso, medial pair of pso below the row p of setae and submedial above row $p$, Th. sterna II-III with ventral setae. reversa

(Fjellberg, 1987)

-Abd. terga I-III with normal arrangement of pso, medial pair in row $p$ of setae and submedial pair below the row $p$ of setae, Th. sterna II-III without ventral setae ..nuda (Fjellberg, 1987)

19. Abd. terga I-V with 33343 or 33353 pso 20

-Abd. terga I-V with 33333 pso

tottabetsuensis (Yosii, 1972)

20. Abd. terga I-V with 33343 pso 21

-Abd. terga I-V with 33353 pso interrupta (Fjellberg, 1987)

21. Tibiotarsal distal whorl with less than 11 setae ....... 22

-Tibiotarsal distal whorl with 11 chatae ...................... 23

22. Tibiotarsal distal whorl with nine setae .......... raxensis (Gisin, 1961)

-Tibiotarsal distal whorl with five setae. chatyrdagi (Kaprus' et al., 2002) comb. nov.

23. Th. terga II and III with s-microetae (ms) 24

-Th. tergum II with s-microsetae (ms), Th. tergum III without s-microsetae (ms), furcal remnant with cuticular furrow nataliae (Fjellberg, 1987)

24. Furcal remnant with cuticular fold 25

-Furcal remnant with finely granulated area, subcoxae 1 with 111 pso and 222 psx. sanjiangensis (Sun and $\mathrm{Wu}, 2012 \mathrm{a}$ ) comb. nov.

25. PAO with three to four lobes, 3.5 times longer that the nearest pso. .koreana (Weiner, 1994)

-PAO with two to three lobes, 2.0 times longer that the nearestpso..... pingicola (Fjellberg, 1987)

26. Th. tergum I with $1+1$ pso ................................. 27

-Th. tergum I with $2+2$ pso ..................................... 51

27. Abd. terga I-III with 444 pso ............................... 28

-Abd. terga I-III with 333 pso ..................................... 29

28. Abd. sterna I-IV with 1112 pso, subcoxae 1 with 233 pso. uralica

(Khanislamova, 1986)

-Abd. sterna I-IV without pso, subcoxae 1 with 111 pso and 222 psx. changbaiensis (Wu and

Sun, 2012) comb. nov.

29. Abd. terga IV-V with 43 or 33 pso ........................ 30

-Abd. terga IV-V with 53, 54 or 4(5)4 pso .................. 45

30. AIIIO with four papillae ...................................... 31

-AIIIO with five papillae ............................................ 33

31. Abd. terga IV-V with 43 pso ................................. 32

-Abd. terga IV-V with 33 pso ........ palissai (Yosii, 1971)

32. Th. tergum II with s-microsetae (ms), Th. tergum III without s-microsetae (ms) ........ absoloni (Börner, 1901b)

-Th. terga II and III with s-microsetae (ms) ..sophyae (Weiner and Kaprus', 2014) comb. nov. 
33. Abd. sternum IV with pso ........................................... 34

-Abd. sternum IV without pso .......................................... 37

34. Tibiotarsal distal whorl with 11 setae ....................... 35

-Tibiotarsal distal whorl with nine setae ......................... 36

35. Th. terga II and III with s-microsetae (ms) .......... alnus

(Fjellberg, 1987)

-Th. tergum II with s-microsetae (ms), Th. tergum III without s-microsetae (ms) pieninensis

(Weiner, 1988) comb. nov.

36. Abd. sterna I-IV with 0001 pso.......................irinae

(Thibaud and Taraschuk, 1997) comb. nov.

-Abd. sterna I-IV with 1111 pso ...........................olenae

(Weiner and Kaprus, 2014) comb. nov.

37. Subcoxae 1 with 111 pso 38

-Subcoxae 1 with 333 pso, furcal remnant with cuticular fold tuvinica Potapov and Stebaeva, 1997

38. Tibiotarsal distal whorl with nine setae ................... 39

-Tibiotarsal distal whorl with 11 setae ............................ 41

39. Subcoxae 1 with $3,3,3$ or $4,4,5$ setae, anal spines not as spiniform setae .

-Subcoxae 1 with 2,3,3 setae, anal spines as spiniform setae pseudoraxensis (Nosek and Christian, 1983)

40. Subcoxae 1 with $3,3,3$ setae caucasica (Weiner and Kaprus', 2014) comb. nov.

-Subcoxae 1 with 4,4,5 setae differens (Bagnall, 1949)

41. Th. terga II and III with s-microsetae (ms) 42 -Th. tergum II with s-microsetae (ms), Th. tergum III without s-microsetae (ms)

42. Furcal remnant with finely granulated area ............. 43

-Furcal remnant with cuticular fold schoetti (Lie-Pettersen, 1896)

43. Abd. $\mathrm{V}$ with $\mathrm{m} 1$ as macrosetae (twice times longer than $\mathrm{p} 1)$, length about $1.6 \mathrm{~mm}$ groenlandica (Tullberg, 1876)

-Abd. V with $\mathrm{m} 1$ as microsetae (twice times shorter than p1), length about $0.67-0.93$ sibirica

(Weiner and Kaprus', 2014) comb. nov.

44. Furcal remnant with cuticular fold, subcoxae 1 with 122 psx ursi (Fjellberg, 1984)

-Furcal remnant with cuticular furrow, subcoxae 1 without psx ..............................gamae (Buşmachiu and Weiner, 2013) comb. nov.

45. Abd. terga IV-V with 53 pso, dorsal setae strongly differentiated .. 46 -Abd. terga IV-V with 54 or 4(5)4 pso, dorsal setae not strongly differentiated . .. 48 46. Th. terga II and III with s-microsetae (ms) ............... 47 -Th. tergum II with s-microsetae (ms), Th. tergum III without s-microsetae (ms), furcal remnant with cuticular fold

sabulosa Babenko, 2007
47. Dorso-lateral setae strongly differentiated, furcal remnant with cuticular fold, maxillary outer lobe without sublobal setae aborigensis (Fjellberg, 1987)

-Dorso-lateral setae slightly differentiated, furcal remnant with finely granulated area, maxillary outer lobe with two setae ..jingyueensis (Sun and Wu, 2012b) comb. nov.

48. Furcal remnant with cuticular fold 49

-Furcal remnant with finely granulated area .................. 50 49. Anterior pso on head: one pso inside Ant. basis and two pso outside, subcoxae 1 with 111 pso +222 psx linderae (Weiner, 1994)

-Anterior pso on head: two pso inside Ant. basis and one pso outside, subcoxae 1 with 111 pso +122 psx .........................................judithae (Weiner, 1994) 50. Abd. sternum IV with $1+1$ pso, anal spines 2.6 times as long as their basal diameter pseudoinya (Weiner and Kaprus', 2014) comb. nov.

-Abd. sternum IV without pso, anal spines 3.2 times as long as their basal diameter inya

(Weiner and Kaprus', 2014) comb. nov.

51. Furcal remnant with finely granulated area, pseudocellar formula: 32/2(1)33/33343 duocellata Babenko and Fjellberg, 2015

-Furcal remnant with cuticular fold, pseudocellar formu1 a: $32 / 2$ ( 3 ) 3( 4 ) 3( 4 )/33( 4 ) 333 quadrituberculata (Börner, 1901a)

52. Head dorsally with 33 pso, body with $0(1) 44 /$ $3334(5) 4$ pso kurtshevae (Martynova, 1981)

-Head dorsally with more pso ... .53

53. Anterior part of head with $4+4$ pso ......................... 54

-Anterior part of head with $10+10 \mathrm{pso}$, posterior part with $9+9$ pso, Th. tergum I with $6+6$ pso, pseudocellar formula: $10,9 / 6,15,15 / 15,19,18,22,9$, subcoxae 1 with 444 pso, AIIIO with 4 papillae multiperforata Gruia, 1973

54. Abd. terga I-III with 544 pso 55

-Abd. terga I-III with 555 pso, Abd. terga IV-V with 67, 4-6 pso respectively. chankaensis

Sun and $\mathrm{Wu}, 2012 \mathrm{~b}$

55. Abd. terga IV-V with 53 pso montana

Weiner, 1994

-Abd. terga IV-V with 64 pso

Wu and Sun, 2012

Open Access This article is distributed under the terms of the Creative Commons Attribution 4.0 International License (http:// creativecommons.org/licenses/by/4.0/), which permits unrestricted use, distribution, and reproduction in any medium, provided you give appropriate credit to the original author(s) and the source, provide a link to the Creative Commons license, and indicate if changes were made. 


\section{References}

Babenko, A. B. (2007). Collembolan fauna of the Turukhansk Territory. Russian Entomological Journal, 16(4), 361-383.

Babenko, A., \& Fjellberg, A. (2015). Subdivision of the tribe Oligaphorurini in the light of new and lesser known species from North-East Russia (Collembola, Onychiuridae, Onychiurinae). ZooKeys, 488, 47-75. doi:10.3897/zookeys.488.8123.

Bagnall, R. S. (1949). Contribution toward a knowledge of the Onychiuridae (Collembola-Onychiuroidea). $V-X$. Annals and Magazine of Natural History, 2(19), 498-511.

Bellinger, P. F., Christiansen, K. A., \& Janssens, F. (2016). Checklist of the Collembola of the world. http://www.collembola.org

Börner, C. (1901a). Vorläufige Mittheilung über einige neue Aphorurinen und zur Systematik der Collembola. Zoologischer Anzeiger, 24(633), 1-15.

Börner, C. (1901b). Über ein neues Achorutidengenus Willemia, sowie 4 weitere neue Collembolenformen derselben Familie. Zoologischer Anzeiger, 24(648), 422-433.

Bremer, K. (1994). Branch support and tree stability. Cladistics, 10(3), 295-304. doi:10.1111/j.1096-0031.1994.tb00179.x.

Bryant, H. N. (1995). Why autapomorphies should be removed: a reply to Yeates. Cladistics, 11(4), 381-384. doi:10.1111/j.1096-0031.1995. tb00097.x.

Buşmachiu, G., \& Weiner, W. M. (2013). Collembola from the Moldavian Banks of Dniester River. New Records. Annales Zoologici, 63(4), 529-535. doi:10.3161/000345413X676759.

Cassagnau, P. (1968). Sur quelques Collemboles nouveaux des Alpes italiennes. Bulletin de la société d'histoire naturelle de Toulouse, 104(1-2), 243-251.

Christian, E. (1986). Onychiurus (Oligaphorura) hackeri n. sp., ein cavernicoler Springschwanz aus Niederösterreich (Hexapoda: Collembola). Annalen des Naturhistorischen Museums in Wien. Serie B für Botanik und Zoologie, 87, 177-180.

Christian, E. (1993). Collembolen aus zwei Windröhren des Ötscherlandes (Niederösterreich). Verhandlungen der ZoologischBotanischen Gesellschaft in Österreich, 130, 157-169.

Christiansen, K., \& Bellinger, P. F. (1980). The Collembola of North America north of the Rio Grande (part 2): Families Onychiuridae and Isotomidae. Grinnell, Iowa: Grinnell College.

Denis, J. R. (1931). Contributo alla conoscenza del“" Microgenton” di Costa Rica II. Bollettino del Laboratorio di Zoologia Generale e Agraria della Facoltà Agraria in Portici, 1931, 69-170.

Fitch, W. M. (1971). Toward defining the course of evolution: minimum change for a specific tree topology. Systematic Zoology, 20(4), 406. doi: $10.2307 / 2412116$.

Fjellberg, A. (1987). Northern species of Onychiurus Gervais, 1841, subgenus Archaphorura Bagnall, 1949 (Collembola: Onychiuridae). Insect Systematics \& Evolution, 18(3), 279-288.

Fjellberg, A. (1998). The Collembola of Fennoscandia and Denmark: Part 1: Poduromorpha. In Fauna entomologica Scandinavica (Vol. 35). Leiden, Boston: Brill.

Fjellberg, A. (1999). The labial palp in Collembola. Zoologischer Anzeiger, 237(4), 309-330.

Giribet, G. (2003). Stability in phylogenetic formulations and its relationship to nodal support. Systematic Biology, 52(4), 554-564. doi:10. 1080/10635150390223730.

Gisin, H. (1954). Description de cinq espèces inédites de Collemboles. Mitteilungen der Schweizerischen Entomologischen Gesellschaft, 27(1), 49-52.

Gisin, H. (1961). Collembolen aus der Sammlung C. Börner des Deutschen Entomologischen Instituts (Apterygota). I. Deutschland und angrenzende Länder. Beiträge zur Entomologie, 11(3-4), 329354.
Goloboff, P. A. (1993). Estimating character weights during tree search. Cladistics, 9(1), 83-91. doi:10.1111/j.1096-0031.1993.tb00209.x.

Goloboff, P. A., Farris, J. S., Källersjö, M., Oxelman, B., Ramıacuterez, M. J., \& Szumik, C. A. (2003). Improvements to resampling measures of group support. Cladistics, 19(4), 324-332. doi:10.1111/j. 1096-0031.2003.tb00376.x.

Goloboff, P. A., Farris, J. S., \& Nixon, K. C. (2008). TNT, a free program for phylogenetic analysis. Cladistics, 24(5), 774-786. doi:10.1111/j. 1096-0031.2008.00217.x.

Gruia, M. (1973). Onychiurus (Oligaphorura) multiperforatus, nouvelle espèce d'Onychiuridae de Roumanie. Travaux de l'Institut de Spéologie Emile Racovitza, 12, 173-176.

Kaprus', I. J., Weiner, W. M., \& Pomorski, R. J. (2002). New data on Ukrainian Oligaphorurini (Collembola, Onychiuridae) with description of three new species of Micraphorura Bagnall, 1949. Annales Zoologici, 52, 353-357.

Lie-Pettersen, O. J. (1896). Norges Collembola, Fortagnelse over de i Norge hidtie observada Arten. Bergens Museums Aarbog, 8, 3-26.

Martynova, E. F. (1981). New genus and new species of springtails (Collembola) from Eastern Siberia. Zoologicheskii Zhurnal, 60(1), 151-157.

Nixon, K. C. (2002). WinClada, version 1.00.08. Published by the author, Ithaca, New York. http://www.cladistics.com

Nosek, J., \& Christian, E. (1983). Onychiurus (Oligaphorura) pseudoraxensis n. sp.-Ein neuer Springschwanz (Hexapoda: Collembola) aus einer niederösterreichischen Höhle. Annalen des Naturhistorischen Museums in Wien. Serie B für Botanik und Zoologie, 397-400.

Pomorski, R. J. (1996). The first instar larvae of Onychiurinae - a systematic study (Collembola: Onychiuridae). Genus, 7(1), 1-102.

Pomorski, R. J. (1998). Onychiurinae of Poland (Collembola: Onychiuridae). Wrocław: Genus (Supplement), Polish Taxonomical Society

Pomorski, R. J., Skarżyński, D., \& Kaprus', I. J. (1998). New Onychiurinae from Crimea (Collembola: Onychiuridae). Genus, 9(3), 253-263.

Potapov, M., \& Stebaeva, S. (1997). Four new species of families Onychiuridae and Isotomidae (Hexapoda, Collembola) from Ubsunur Hollow (Tuva, Russia). Miscelánea zoológica, 20, 119 131.

Shvejonkova, Y., \& Potapov, M. (2011). Three new species of Oligaphorurini (Collembola: Onychiuridae) without anal spines from European part of Russia. Russian Entomological Journal, 20(4), 351-360.

Simón, J. C. (1994). Neuvas especies de la subfamilia Onychiurinae de la p sula Ibérica. Publicaciones de Biología de la Universidad de Navarra, Serie Zoológica, 24, 61-74.

Stach, J. (1930). Verzeichnis der Apterygognea Ungarns 1929 Simon. Annales Historico-Naturales Musei Nationalis Hungarici, 26, 269-312.

Stach, J. (1933). Zwei neue Arten von Onychiurus Gerv. (Collembola) aus Polen. Bulletin del Academie Polonaise des Sciences, 2, 235 241.

Sun, X., \& Wu, D. H. (2012a). A newly recorded tribe of family Onychiuridae (Collembola, Poduromorpha) with a new species and a newly recorded species from northeast China. Acta Zootaxonomica Sinica, 37(1), 105-110.

Sun, X., \& Wu, D. H. (2012b). Two new species of the tribe Oligaphorurini Bagnall, 1949 (Collembola: Onychiuridae) from northeast China. Zootaxa, 3526, 45-52.

Thibaud, J.-M., \& Taraschuk, M. (1997). Collemboles interstitiels des sables d'Ukraine. Revue française d'entomologie, 19(3-4), 111116.

Tullberg, T. (1876). Collembola borealia. Öfversigt af Kongl. vetenskapsakademiens förhandlingar, 1876, 23-42. 
Weiner, W. M. (1988). New species from the genus Micraphorura Bagnall, 1949 (Onychiuridae, Collembola). Acta Zoologica Cracoviensia, 31(9), 383-386.

Weiner, W. M. (1994). Onychiurinae Bagnall of North Korea: species with small postantennal organs (Collembola, Onychiuridae). Bulletin de la Société entomologique de France, 99(1), 31-40.

Weiner, W. M. (1996). Generic revision of Onychiurinae (Collembola: Onychiuridae) with a cladistic analysis. Annales de la Société entomologique de France, 32(2), 163-200.

Weiner, W. M., \& Kaprus', I. J. (2014). Revision of Palearctic species of the genus Dimorphaphorura (Collembola: Onychiuridae: Onychiurinae: Oligaphorurini) with description of new species. Journal of Insect Science, 14(74), 1-30. doi:10.1093/jis/14.1.74.
Wilkinson, M. (1992). Ordered versus unordered characters. Cladistics, 8(4), 375-385. doi:10.1111/j.1096-0031.1992.tb00079.x.

Wu, D., \& Sun, X. (2012). Review of Chinese Oligaphorurini (Collembola, Onychiuridae) with descriptions of two new Palaearctic species. ZooKeys, 192(192), 15-26. doi:10.3897/ zookeys.192.2959.

Yeates, D. (1992). Why remove autapomorphies? Cladistics, 8(4), 387389. doi:10.1111/j.1096-0031.1992.tb00080.x.

Yosii, R. (1971). Collembola of Khumbu Himal. Khumbu Himal. Universitätsverlag Wagner, Innsbruck-München, 4(1), 80-130.

Yosii, R. (1972). Collembola from the Alpine region of Mt. Poroshiri in the Hidaka mountains, Hokkaido. Memoirs of the National Science Museum, Tokyo, 5, 75-99. 